Article

\title{
Environmentally Friendly Surface Modification Treatment of Flax Fibers by Supercritical Carbon Dioxide
}

\author{
Maria Carolina Seghini ${ }^{1,2, *}$, Fabienne Touchard ${ }^{2}$, Laurence Chocinski-Arnault ${ }^{2}$, \\ Vincent Placet ${ }^{3}{ }^{\circledR}$, Camille François ${ }^{3,4}$, Laurent Plasseraud ${ }^{4}\left(\mathbb{D}\right.$, Maria Paola Bracciale ${ }^{1}$, \\ Jacopo Tirillò ${ }^{1}$ and Fabrizio Sarasini ${ }^{1, *(\mathbb{D})}$ \\ 1 Department of Chemical Engineering Materials Environment, Sapienza-Università di Roma, 00184 Roma, \\ Italy; mariapaola.bracciale@uniroma1.it (M.P.B.); jacopo.tirillo@uniroma1.it (J.T.) \\ 2 Département Physique et Mécanique des Matériaux, ENSMA, Institut PPRIME, CNRS-ENSMA-Université \\ de Poitiers, 86961 Futuroscope CEDEX, France; fabienne.touchard@ensma.fr (F.T.); \\ laurence.chocinski@ensma.fr (L.C.-A.) \\ 3 Department of Applied Mechanics, CNRS/UFC/ENSMM/UTBM, FEMTO-ST Institute, University of \\ Bourgogne Franche-Comté, 25030 Besançon, France; vincent.placet@univ-fcomte.fr (V.P.); \\ camille.francois@u-bourgogne.fr (C.F.) \\ 4 Catalysis, and Stereochemistry Team-OCS, CNRS/UB, Organometallics, ICMUB Institute, University of \\ Bourgogne Franche-Comté, 21000 Dijon, France; Laurent.plasseraud@u-bourgogne.fr \\ * Correspondence: mariacarolina.seghini@uniroma1.it (M.C.S.); fabrizio.sarasini@uniroma1.it (F.S.); \\ Tel.: +39-0644585314 (M.C.S.); +39-0644885408 (F.S.)
}

Academic Editor: Gregory Chatel

Received: 23 December 2019; Accepted: 19 January 2020; Published: 21 January 2020

\begin{abstract}
The present work investigates the effects of an environmentally friendly treatment based on supercritical carbon dioxide $\left(\mathrm{scCO}_{2}\right)$ on the interfacial adhesion of flax fibers with thermoset matrices. In particular, the influence of this green treatment on the mechanical (by single yarn tensile test), thermal (by TGA), and chemical (by FT-IR) properties of commercially available flax yarns was preliminary addressed. Results showed that $\mathrm{scCO}_{2}$ can significantly modify the biochemical composition of flax fibers, by selectively removing lignin and hemicellulose, without altering their thermal stability and, most importantly, their mechanical properties. Single yarn fragmentation test results highlighted an increased interfacial adhesion after $\mathrm{scCO}_{2}$ treatment, especially for the vinylester matrix, in terms of reduced debonding and critical fragment length values compared to the untreated yarns by $18.9 \%$ and $15.1 \%$, respectively. The treatment was less effective for epoxy matrix, for which debonding and critical fragment length values were reduced to a lesser extent, by $3.4 \%$ and $3.7 \%$, respectively.
\end{abstract}

Keywords: flax fibers; supercritical carbon dioxide; natural fibers; interface/interphase; surface modification treatments

\section{Introduction}

The development of natural fiber composites is currently under the spotlight not only in the academic but also in the industrial sector due to a host of reasons including their low density, low environmental impact, and competitive specific mechanical properties [1]. In this regard, flax fibers show a favorable combination of properties that make them a material of choice to reinforce polymers, such as their wide availability throughout the world, their morphology characterized by significant length (around $2-5 \mathrm{~cm}$ ) with thick secondary walls $(5-15 \mu \mathrm{m})$, good mechanical properties caused by a small microfibrillar angle, and high cellulose content and low density [2]. Therefore, flax fibers have 
been extensively investigated over the last twenty years [3-5], and two issues have been highlighted that still prevent their full exploitation as reinforcement in composite materials, i.e., the variability in properties and the poor interfacial adhesion with most polymer matrices. As regards the first issue, recent studies have demonstrated that tensile properties of flax fibers are not significantly affected over time irrespective of the fiber yield and variety and that the scattering in the specific mechanical properties lies in the same range of glass fibers [6]. According to Baley et al. [7], excellent composite properties with reduced variability can be reached if the fiber supply chain is carefully controlled and the manufacturing processes are optimized.

The quality of the fiber/matrix interface is another topic of considerable interest, as the poor compatibility with polymer matrices represents a major limitation for the industrial exploitation of natural fibers. Their peculiar hydrophilic surfaces prevent them from achieving a proper interfacial adhesion with the more hydrophobic polymer matrices, which leads to poor mechanical properties of the resulting composites. In addition, moisture retention can trigger dimensional changes, thus reducing the mechanical performance and increasing the proneness to microbiological degradation [8]. While numerous studies are still addressing the surface modification of natural fibers with a view to making them as much as possible compatible with composite materials requirements [9-11], their industrial implementation is compromised by the need to manage the large amounts of chemicals involved. These surface modification treatments range from chemical treatments [12-17] to physical treatments [18-20]. In particular, plasma modification of the surface of natural fibers can not only cause etching of the material and a related better physical adhesion but also the addition of free radicals. A further possibility is represented by the use of polymerizing gases, thus inducing a plasma polymerization or grafting on the fibers' surface, as recently demonstrated for flax fibers with a tetravinylsilane coating deposited via Plasma Enhanced Chemical Vapour Deposition (PECVD) [21]. This treatment was able to increase the interfacial shear strength values by $114 \%$ and $71 \%$ in epoxy and vinylester composites, respectively. A more recent approach deals with the grafting of nanostructures on fibers' surface to increase the adhesion with the polymer matrix [22-24] and/or induce multifunctionalities [25,26]. Ajith et al. [24] decorated the flax fiber yarns with hydrous zirconia nanoparticles by hydrolysis of zirconium oxychloride solution and by single fiber pull-out tests with an epoxy matrix reported an increase in the bonding strength by $65 \%$. Wang et al. [27] grafted $\mathrm{TiO}_{2}$ nanoparticles on flax fibers and with the optimized amount of $2.34 \mathrm{wt} \%$ they obtained enhancements in both tensile strength of the flax fibers and interfacial shear strength with epoxy resin by $23.1 \%$ and $40.5 \%$, respectively. In Reference [22], the authors developed a simple spray-coating process to deposit carbon nanotubes (CNTs) over the surface of ramie fibers. This coating was found to enhance the flexural strength and modulus of an epoxy-based composite by $38.4 \%$ and $36.8 \%$, respectively, while a microdebonding test highlighted an increase in the interfacial shear strength by $25.7 \%$. Sarker et al. [23] have recently reported the coating of graphene oxide (GO) and graphene flakes $(\mathrm{G})$ on jute fibers and an interfacial shear strength enhancement by $\sim 236 \%$ compared to untreated fibers. However, these processes are often complex because there is a need to avoid nanostructures' aggregation.

An envisaged challenge is to develop a pretreatment able to tailor the properties of natural fibers for their subsequent successful application in high-performance plant fiber composites but with limited costs and environmental impact. A less investigated approach deals with the use of supercritical fluids, which are substances above critical conditions (temperature and pressure) that show properties (e.g., density, viscosity, diffusion coefficient) intermediate between those of liquids and gases [28]. These fluids provide uncommon possibilities for selective extractions and fractionations, separation and purification, materials processing, and synthesis [29-32].

Among the different supercritical fluids, supercritical $\mathrm{CO}_{2}\left(\mathrm{scCO}_{2}\right)$ has attracted considerable interest because of its relatively moderate critical temperature of $31.1^{\circ} \mathrm{C}$ and pressure of $73.8 \mathrm{bar}$ [33]. $\mathrm{scCO}_{2}$ is a green attractive alternative to chemical solvents because it is inexpensive, essentially nontoxic, nonflammable, and can be easily recovered and recycled after use [28]. The interactions of supercritical fluids with lignocellulosic materials have been the subject of extensive investigations. The 
extent of dissolutions in wood species was investigated by Li and Kiran [33], and the authors reported that the extractions in carbon dioxide, ethylene, nitrous oxide, and n-butane were not significant. In Reference [34], the damage in several man-made and cellulose fabrics (cotton, viscose) after treatment in supercritical $\mathrm{CO}_{2}$ was assessed. The authors reported no shrinkage of the fabrics, but stress-strain measurements showed decreased tensile strength and elongation after treatment in carbon dioxide for $4 \mathrm{~h}$ at $160{ }^{\circ} \mathrm{C}$ and 300 bar. Depolymerization of cellulosic fibers was suggested as the result of a combination of heat, supercritical carbon dioxide, and treatment time due to cleavage of acetal bonds. This study highlights potential treatments of cellulose fibers (cotton and viscose) up to $140{ }^{\circ} \mathrm{C}$ or 160 ${ }^{\circ} \mathrm{C}$ but for a shorter time. Daza Serna et al. [35] used $\mathrm{scCO}_{2}$ for the pretreatment of lignocellulosic rice husk ( $80^{\circ} \mathrm{C}, 270$ bar, $\left.10 \mathrm{~min}\right)$. The authors reported a significant delignification effect but no reductions in crystallinity and enzymatic digestibility.

Much limited attention has received the use of $\mathrm{scCO}_{2}$ for the surface treatment of plant fibers intended as reinforcement of polymer matrices. Gutiérrez et al. [36] studied the effect of supercritical carbon dioxide on the properties of Curauá fibers. The treatment with supercritical $\mathrm{CO}_{2}$ resulted in the partial lignin extraction from the fibers and fiber fibrillation. This result was confirmed by a FT-IR and thermogravimetric analysis. In particular, the untreated Curauá fibers showed the presence of three steps of mass loss: a first stage at a temperature of $100{ }^{\circ} \mathrm{C}$, attributed to the presence of moisture in the fiber; a second stage around $300{ }^{\circ} \mathrm{C}$ associated with the hemicellulose and cellulose decomposition; and a final step of mass loss at a temperature of $400{ }^{\circ} \mathrm{C}$, linked to the lignin decomposition and the production of volatile substances. The thermogravimetric curves found for the $\mathrm{scCO}_{2}$ treated fibers showed only the presence of the first two decomposition steps, confirming the lignin extraction produced by the supercritical solvent. Two series of biocomposites, one plasticized with dioctyl phthalate (DOP) and another with triethyl citrate (TEC), were prepared by extrusion. Fibrillation and uniform distribution of fibers in the cellulose acetate matrix were observed for both biocomposites.

Recently, a supercritical $\mathrm{CO}_{2}$ treatment has been developed in order to reduce the hygroscopic behavior and modify the physicochemical properties of hemp fibers $[37,38]$. The authors reported a decrease in the hygroscopic behavior of hemp fibers after the supercritical $\mathrm{CO}_{2}$ treatment ascribed to the extraction of polysaccharides from the fiber structure, such as hemicellulose and pectin, rich in hydroxyl groups. In addition, a decrease in the tensile stiffness of the fibers, as well as a more brittle fracture, was detected, coupled with a better fiber fineness.

These preliminary studies confirm that $\mathrm{scCO}_{2}$ treatment may represent a promising solution in order to tailor the adhesion of natural fibers with polymer matrices, even if the knowledge of the effects of such treatment on the mechanical, thermal, and morphological properties of natural fibers needs to be analyzed in detail. In this framework, the aim of the present work was to assess the suitability of a supercritical carbon dioxide treatment to improve the interfacial adhesion of flax yarns with two different thermoset matrices, namely epoxy and vinylester, with a view to designing chemically efficient products and processes that reduce or eliminate the use or generation of hazardous substances. The impact of this green treatment was evaluated by performing chemical, mechanical, thermal, and morphological characterizations at the yarn level and by micromechanical single-fiber fragmentation tests (SFFT) for interfacial quality assessment.

\section{Results and Discussion}

\subsection{Characterization of Flax Yarns after $\mathrm{scCO}_{2}$ Treatment}

The morphology of flax yarns after the supercritical carbon dioxide treatment was preliminarily investigated by scanning electron microscopy and the results are included in Figures 1 and 2 for untreated and $\mathrm{scCO}_{2}$ treated flax yarns, respectively. Comparing the surface of the untreated flax yarn (Figure 1) and $\mathrm{scCO}_{2}$ treated flax yarn (Figure 2), it is possible to observe that the supercritical carbon dioxide treatment was able to remove impurities from the yarn surface. The wax-like substances decreased after the treatment, producing a relatively clean flax yarn surface, but at higher magnification, 
a phenomenon of surface peeling off was noted (Figure 2B). As reported by Zhang et al. [39], this peeling effect is due to changes to the surface morphology of the flax fibers occurring in supercritical carbon dioxide and that non-cellulosic constituents such as lignin, pectin, and hemicellulose have been removed in supercritical carbon dioxide fluid, as supported by the subsequent FT-IR results. In this regard, François et al. [38] reported a decrease in lignin content of hemp fibers up to $24.5 \%$ after $\mathrm{scCO}_{2}$ treatment.
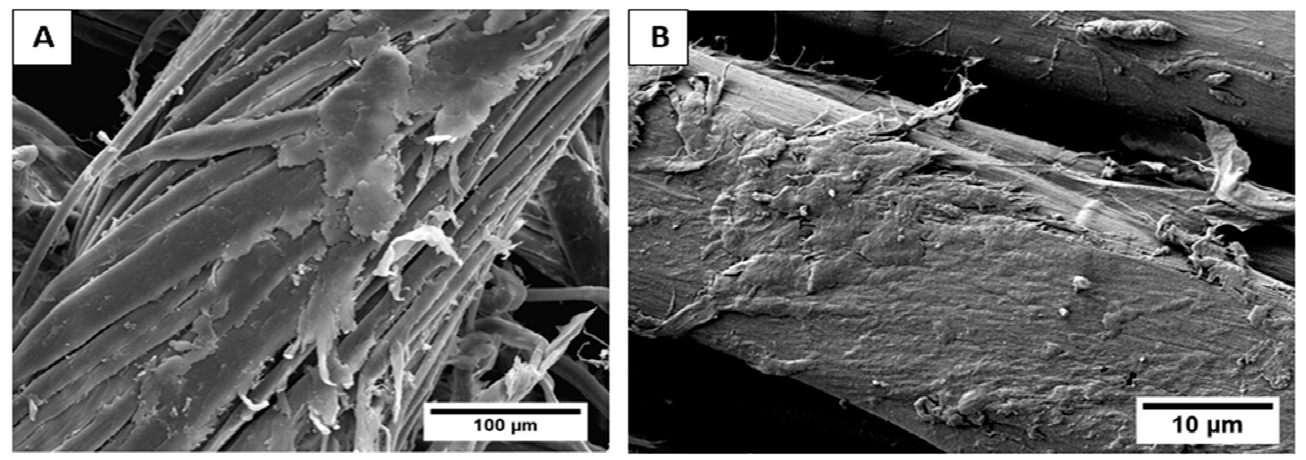

Figure 1. SEM micrographs showing the untreated flax yarn (A) and a detail of the flax fiber surface (B).
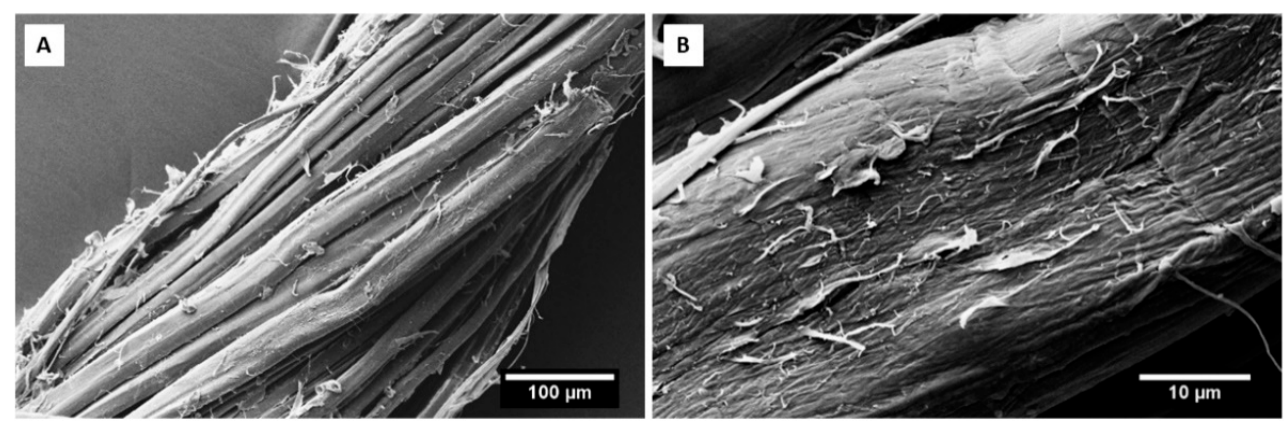

Figure 2. SEM micrographs showing the supercritical $\mathrm{CO}_{2}$ treated flax yarn $(\mathrm{A})$ and a detail of the flax fiber surface $(\mathbf{B})$.

The effect of the chemical treatment on the surface composition of flax fibers was studied by Fourier-Transform Infrared (FT-IR) analysis. A comparison between the FT-IR spectra of as-received and $\mathrm{scCO}_{2}$ treated flax yarns is shown in Figure 3.

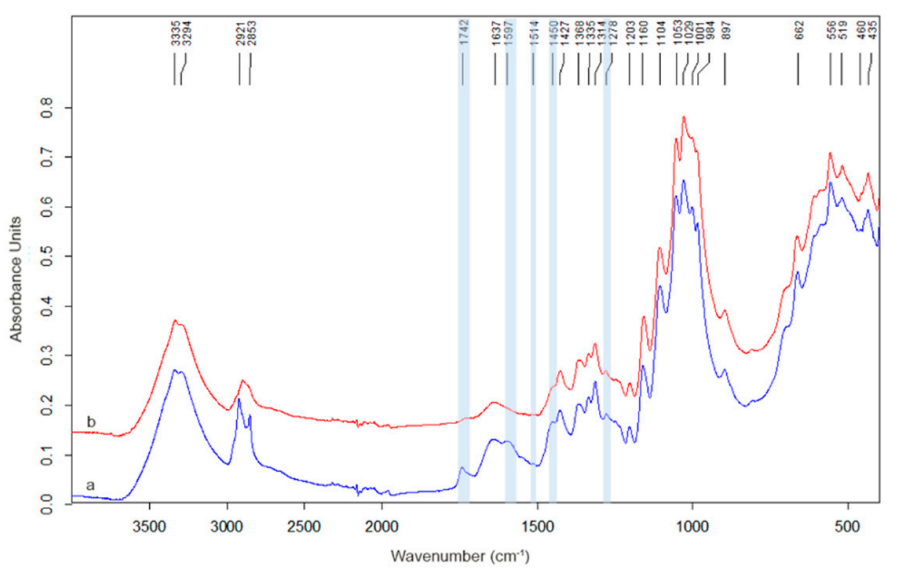

Figure 3. FT-IR spectra of as-received (a) and supercritical $\mathrm{CO}_{2}$ treated flax yarns (b). The modifications resulting from the treatment are highlighted in light blue. 
The spectral analysis revealed that the untreated flax fiber consists of alkene, esters, aromatics, ketone, and alcohol belonging to cellulose, hemicellulose, and lignin (Table 1), as already reported in $[21,40]$.

Table 1. Assignment of the main ATR-FTIR bands of flax fibers [21].

\begin{tabular}{cc}
\hline Wavenumber $\left(\mathbf{c m}^{-\mathbf{1}} \mathbf{)}\right.$ & Band Assignments $^{*}$ \\
\hline $3700-3000$ & $v \mathrm{OH}$ \\
$2990-2754$ & $\nu \mathrm{CH}$ of cellulose and hemicellulose \\
1742 & $\nu \mathrm{C}=\mathrm{O}$ of hemicellulose \\
1637 & $\delta \mathrm{C}=\mathrm{C}$ and $d \mathrm{CH}$ in methyl, methylene and methoxyl groups of lignin \\
$1597,1514,1450$ & $\delta \mathrm{CH}, \delta \mathrm{CH}$ of cellulose and $\omega \mathrm{CH}_{2}$ in cellulose and hemicellulose \\
$1427,1368,1314$ & $\tau \mathrm{C}-\mathrm{H}_{2}$ of cellulose \\
1278 & $\nu \mathrm{C}-\mathrm{O}-\mathrm{C}$ and $v \mathrm{C}-\mathrm{C}$ of polysaccharide components (mainly cellulose) \\
$1248,1160,1104,1029$ & $\beta \mathrm{C}-\mathrm{OH}$ of cellulose and hemicellulose \\
1053 & $\beta$-glycosidic linkages between the sugars units in cellulose \\
897 & $* v=$ stretching; $\delta=$ bending; $d=$ deformation; $\omega=$ wagging; $\tau=$ twisting.
\end{tabular}

Upon $\mathrm{CO}_{2}$ supercritical treatment, slight shifts could be observed for the characteristic bands of flax. The stretching vibration of $\mathrm{C}-\mathrm{O}-\mathrm{C}$ and the bending vibration of $\mathrm{C}-\mathrm{H}$ were shifted from $1161 \mathrm{~cm}^{-1}$ to $1157 \mathrm{~cm}^{-1}$ and from $897 \mathrm{~cm}^{-1}$ to $896 \mathrm{~cm}^{-1}$, respectively. Furthermore, a visible reduction of the bands at $1742 \mathrm{~cm}^{-1}$ and $1248 \mathrm{~cm}^{-1}$ of hemicellulose [41] and at $1597 \mathrm{~cm}^{-1}, 1514 \mathrm{~cm}^{-1}$, and $1450 \mathrm{~cm}^{-1}$ of lignin was observed. These results confirm the removal of amorphous non-cellulosic compounds produced by supercritical $\mathrm{CO}_{2}$. Supercritical carbon dioxide fluid can infiltrate into flax fibers while causing their swelling, which favors the re-arrangements and re-crystallization of the molecule chains, thus inducing the shifts of the characteristic bands of treated flax fibers. On the other hand, the lignin structure in the flax fibers was easily destroyed and hydrolyzed in supercritical carbon dioxide. Carbon dioxide can also have a plasticization effect on flax fibers in the supercritical state and the increased mobility of the macromolecular chains can induce their rearrangement under high-temperature exposure, which should result in an increase in the crystallinity index $[39,42]$. These assumptions are confirmed by the values of the crystallinity index (CI) of cellulose calculated for the different flax yarns. The CI is an important parameter that refers to the relative crystallinity of the fiber samples, and the higher the value of $\mathrm{CI}$, the greater the crystalline cellulose content and thus, the greater the efficiency of the $\mathrm{scCO}_{2}$ treatment in removing the amorphous components from flax [43]. Semiquantitative measurement of the crystallinity index of cellulose was evaluated as the intensity ratio between the IR absorption bands at 1427 and $897 \mathrm{~cm}^{-1}\left(\mathrm{I}_{1427} / \mathrm{I}_{897}\right)$, which are assigned to $\mathrm{CH}_{2}$ bending mode of cellulose and of the $\mathrm{CH}$ in $\beta$-glycosidic linkages between monosaccharides [44]. The cellulose IR crystallinity index calculated after the $\mathrm{CO}_{2}$ treatment increased by more than 65\% (1.68) compared to untreated flax fiber (1.01), values that allowed a comparison between the untreated and treated states of flax yarns and confirmed the removal of amorphous constituents. The same conclusions were drawn in Reference [38], where the authors measured, by chemical analysis, a significant reduction after supercritical treatment in the content of three monosaccharides, namely rhamnose (Rha), galacturonic acid (GalA), and xylose (Xyl). Rha and GalA are the main components of pectin, while Xyl is linked to hemicellulose. NMR analysis performed on extracts collected in the supercritical carbon dioxide treatment procedure showed the presence of lignins and monosaccharide composition of isolated compounds [39]. A summary of the effects produced by the $\mathrm{scCO}_{2}$ treatment on flax fibers is schematically reported in Scheme 1. 


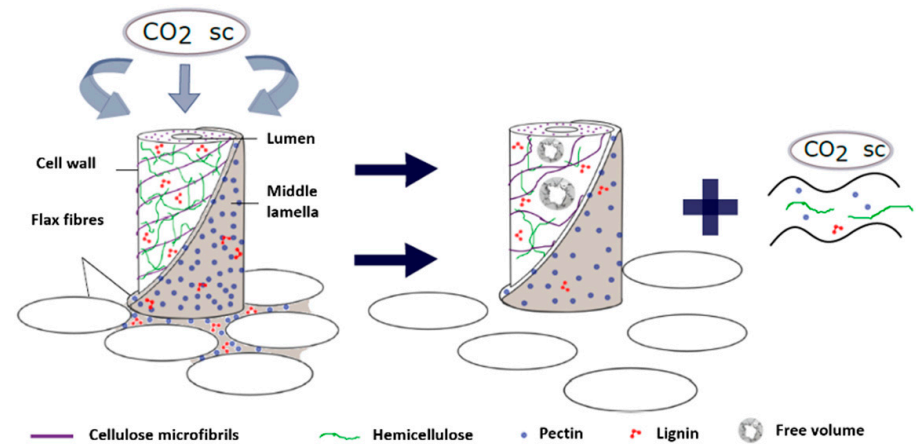

Scheme 1. Effects of $\mathrm{scCO}_{2}$ treatment on flax fibers.

The influence of the supercritical $\mathrm{CO}_{2}$ treatment on the thermal properties of the flax yarns was investigated using thermogravimetric analysis. In Figure 4, the thermograms for the as-received and the treated flax yarns are reported.
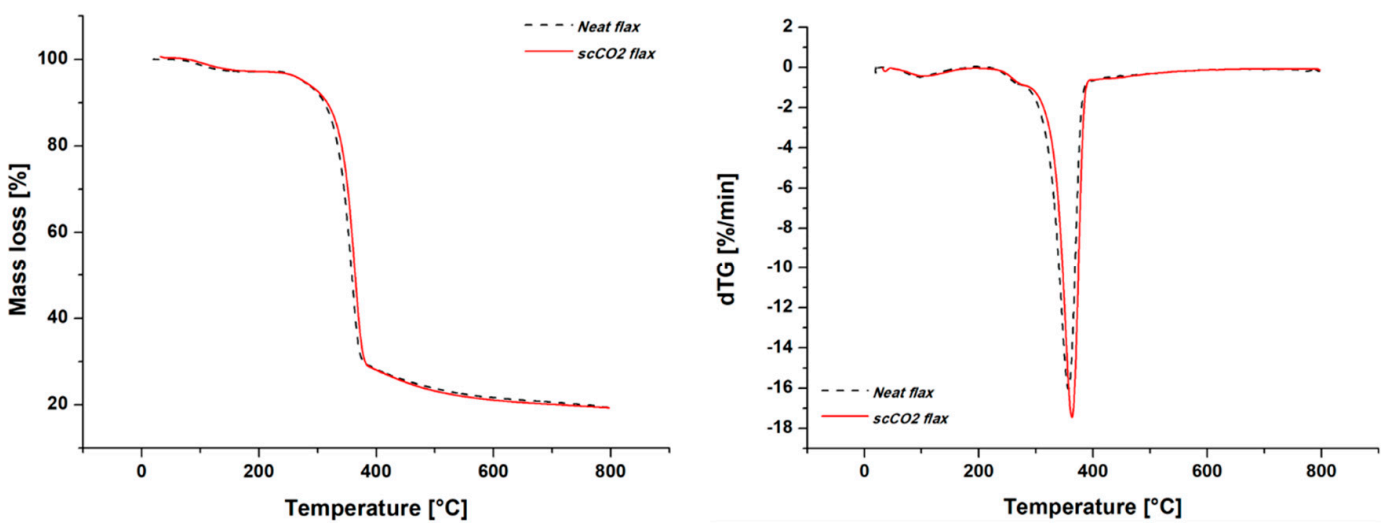

Figure 4. TGA thermograms and derivative thermogravimetry (dTG) curves of flax yarns before and after $\mathrm{scCO}_{2}$ treatment.

The thermogram of the untreated flax yarns exhibited the typical three peaks in the derivative curve: the first mass loss, at about $60-120^{\circ} \mathrm{C}$, is related to the release of water occurring mostly in the amorphous region of cellulose; the second peak, at about $240-280^{\circ} \mathrm{C}$, is attributed to the decomposition of the non-cellulosic components such as pectin and hemicellulose; the third mass loss peak, at about $340-360^{\circ} \mathrm{C}$, is due to the cellulose degradation $[45,46]$. In the supercritical $\mathrm{CO}_{2}$ treated flax yarns, no significant changes in the thermal degradation behavior were detected, with the exception of a slight removal of hemicellulose and pectin components as supported by the higher values of the maximum degradation temperature and of the temperature of $10 \%$ weight loss compared to untreated flax yarns (Table 2).

Table 2. Results of the thermogravimetric analysis for the untreated and $\mathrm{scCO}_{2}$ treated flax yarns.

\begin{tabular}{ccc}
\hline & $\begin{array}{c}\text { Maximum Degradation } \\
\text { Temperature }\left[{ }^{\circ} \mathbf{C}\right]\end{array}$ & $\begin{array}{c}\text { Temperature of 10\% Weight Loss } \\
{\left[{ }^{\circ} \mathbf{C}\right]}\end{array}$ \\
\hline Flax yarn (neat) & 357.2 & 311.3 \\
Flax supercritical $\mathrm{CO}_{2}$ & 363.4 & 313.9 \\
\hline
\end{tabular}

Contrary to FT-IR results, the thermogravimetric analysis did not highlight a significant lignin degradation after supercritical $\mathrm{CO}_{2}$ treatment. In general, the weight loss of lignin occurs slowly over a broader temperature range than cellulose and hemicellulose components [47]. The lignin decomposition starts at relatively low temperatures, $\left(200-275^{\circ} \mathrm{C}\right)$, but the main process occurs around $400-450^{\circ} \mathrm{C}$, with 
the formation of by-products such as aromatic hydrocarbons, phenolics, and hydroxyphenolics [48]. Comparing the thermograms obtained for the untreated and treated flax yarns, no difference was highlighted in a temperature range around $400-450{ }^{\circ} \mathrm{C}$. Even untreated flax fibers did not show significant degradation in the $400-450{ }^{\circ} \mathrm{C}$ temperature range. This can be ascribed to the low amount of lignin in flax fibers because it is usually dictated not only by the genetic pool of the plant but also by harvesting parameters. In fact, in order to make easier the extraction of flax fibers, it is preferable to keep the lignin content to a low level [1]. These results are in line with the ones obtained by François et al. on hemp fibers [38], where only a decrease in the third peak, related to partial lignin extraction, was observed in $\mathrm{scCO}_{2}$ treated samples. Indeed, hemp fibers are usually characterized by higher lignin content compared to flax fibers [1].

Mechanical characterization of untreated and $\mathrm{scCO}_{2}$ treated flax yarns was performed in order to investigate the effect of the treatment on their tensile behavior. The scatter of the tensile strength of flax yarns was statistically analyzed using a two-parameter Weibull distribution according to Equation (1):

$$
P_{r}(\sigma)=1-\exp \left[-\left(\frac{\sigma}{\sigma_{0}}\right)^{m}\right]
$$

where $P_{r}(\sigma)$ is the cumulative probability of failure as a function of applied stress $\sigma, m$ is the Weibull modulus (related to the dispersion of the data), and $\sigma_{0}$ is the characteristic strength. Equation (2) provides the estimator, $P_{f}$, used for the evaluation of failure probability:

$$
P_{f}=\frac{i-0.5}{N}
$$

where $N$ is the number of yarns tested and $i$ is the rank of data point for each yarn.

The effects of the supercritical $\mathrm{CO}_{2}$ on the mechanical performance of flax yarns are reported in Table 3.

Table 3. Tensile properties of untreated and $\mathrm{scCO}_{2}$ treated flax yarns and the corresponding Weibull parameters.

\begin{tabular}{ccccccc}
\hline Specimen & $\mathbf{F}_{\max }[\mathbf{N}]$ & $\begin{array}{c}\text { Diameter } \\
{[\mu \mathrm{m}]}\end{array}$ & $\boldsymbol{\sigma}_{\mathbf{f}}[\mathbf{M P a}]$ & $\mathcal{\varepsilon}_{\mathbf{f}}[\%]$ & $\begin{array}{c}\text { Characteristic } \\
\text { Strength } \boldsymbol{\sigma}_{\mathbf{0}} \\
{[\mathbf{M P a}]}\end{array}$ & $\begin{array}{c}\text { Weibull } \\
\text { Modulus, } \mathbf{m}\end{array}$ \\
\hline Neat flax & $19.8 \pm 4.8$ & $327 \pm 96$ & $236 \pm 57$ & $3.40 \pm 0.42$ & 257 & 5.02 \\
$\mathrm{scCO}_{2}$ flax & $20.4 \pm 3.5$ & $350 \pm 68$ & $211 \pm 36$ & $1.40 \pm 0.15$ & 226.1 & 7.10 \\
\hline
\end{tabular}

If the maximum force values obtained for untreated and treated flax yarns are compared, it is possible to highlight that the supercritical $\mathrm{CO}_{2}$ process does not produce a change of the load-bearing ability of the yarns. However, a slight reduction in the tensile strength value was observed, passing from a value of $236 \pm 57 \mathrm{MPa}$ to a value of $211 \pm 36 \mathrm{MPa}$ for the as-received and the $\mathrm{CO}_{2}$ treated flax yarns, respectively. This decrease is strictly dependent on the increase in the average diameter of yarns produced by the exposure to the supercritical fluid with higher individualization of fibers inside the yarn, as observed in single hemp fibers by Francois et al. [38]. Although not directly investigated in the present work, it is likely to suppose also a change in the twist angle of the yarns as a result of $\mathrm{CO}_{2}$ treatment. In addition, from results reported in Table 3, it is possible to notice that an increase in brittleness of flax yarns occurred after the exposure to the supercritical fluid. In the present case, the effects on the biochemical composition of the flax yarns are balanced by the slight increase in cellulose crystallinity, while the increased brittle behavior can be ascribed to the nucleation of small defects in the fiber cell wall after the depressurization step that prevented an extensive deformation [38].

The experimental results, obtained for the as-received and the $\mathrm{scCO}_{2}$ treated flax yarns, and statistically analyzed using a two-parameter Weibull distribution, are reported in Figure 5. A quasi-linear trend was found for both untreated and treated flax yarns, which suggests that the 
yarn failure depends on the presence of a single population of flaws on the flax yarn surface. The supercritical $\mathrm{CO}_{2}$ treatment did not result in a change in the nature of the fiber defects.

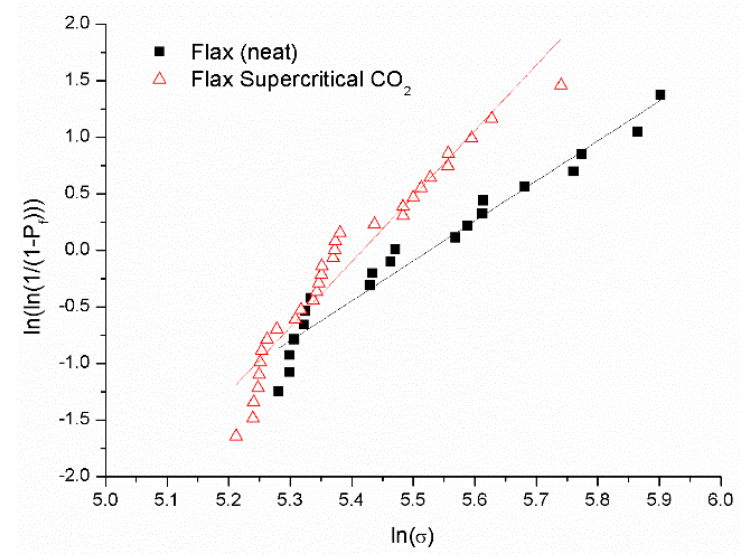

Figure 5. Weibull distribution plots for strength measured for untreated and supercritical $\mathrm{CO}_{2}$ treated flax yarns.

\subsection{Interfacial Quality Assessment by Single Yarn Fragmentation Test}

Fragmentation tests have been performed for the untreated and the $\mathrm{scCO}_{2}$ treated flax yarns with both epoxy and vinylester resins. The critical fragment length was calculated according to Equation (3):

$$
l_{c}=\frac{4}{3} \cdot \overline{1}
$$

where $\overline{1}$ is the average value of the fragment length. For each sample, the yarn diameter and fragment lengths were measured in the gauge length zone, as depicted in Figure 6. In particular, the fragment lengths were determined as the average values between the internal and the central points of the breaking zones. In a previous publication [49], the authors demonstrated by micro-CT that the dark region around each yarn breakpoint represents the debonding length $\left(l_{\text {debonding }}\right)$ at the flax yarn/matrix interface.

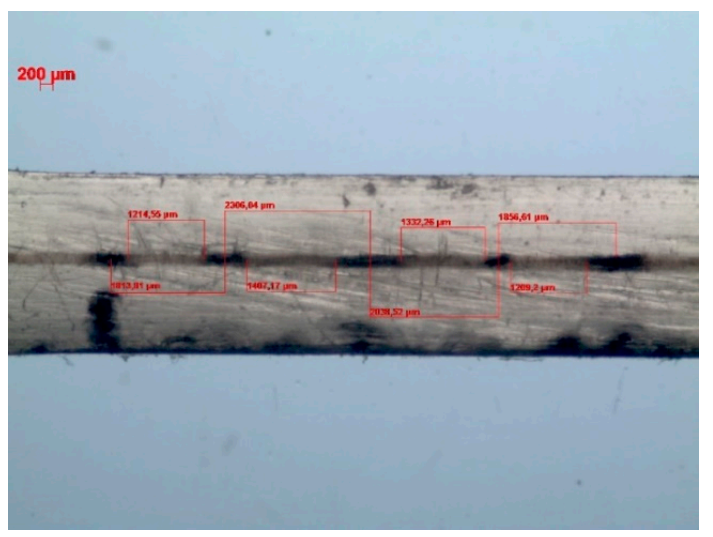

Figure 6. Typical optical micrograph of a fragmented flax yarn in an epoxy matrix: measurement of the yarn fragment length $l$.

These length values were measured by optical microscopy (Figure 7) and the results are summarized in Table 4. For each family of single yarn composites, at least 10 fragmentation tests were carried out. From the results, it is possible to observe that the $\mathrm{scCO}_{2}$ treatment produced a slight reduction in the critical length of flax yarns in both epoxy and vinylester matrices. However, an assessment of the interfacial adhesion quality entirely based on the comparison of critical length is not sound in 
the present case, as the flax yarn strength changed after the surface treatment [50]. There is a strong relationship between the fragment length value and the yarn tensile strength: the greater the failure strength of yarn, the greater the length needed to reach this load and provide fragmentation. For this reason, it should not be proper to evaluate the differences in interfacial bond of the different flax yarn/epoxy and flax yarn/vinylester systems in terms of critical fragment length. However, a comparison between the different values found for the same flax yarn family with the epoxy and vinylester matrices is feasible. The two thermoset systems exhibited different results. From values reported in Table 4, it is possible to infer how the flax/epoxy samples are characterized by smaller values of critical lengths than the flax/vinylester ones, indicating a better adhesion quality. This difference between the epoxy and vinylester systems can be related to the different abilities of the two polymer resins to wet the surface of flax yarns.
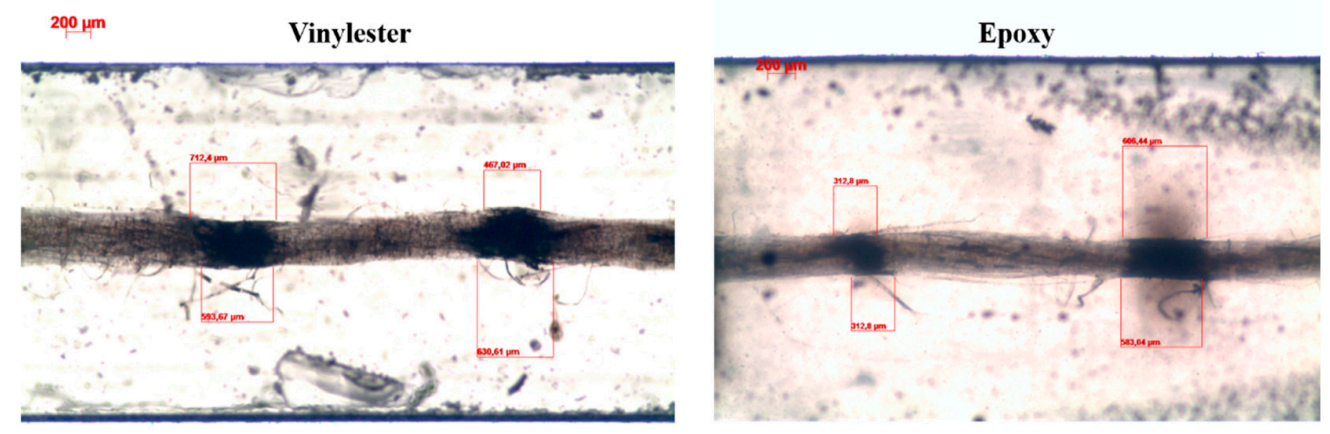

Figure 7. Typical optical micrographs of fragmented flax yarns in vinylester and epoxy matrices: measurement of the debonding length $\left(l_{\text {debonding }}\right)$.

Table 4. Critical fragment length and debonding length values for the different single yarn composites.

\begin{tabular}{cccc}
\hline Matrix & Flax Yarn & $\mathbf{1}_{\mathbf{c}}[\boldsymbol{\mu m}]$ & $\mathbf{1}_{\text {debonding }}[\boldsymbol{\mu m}]$ \\
\hline Epoxy & Neat & $2687 \pm 631$ & $444 \pm 49$ \\
& $\mathrm{scCO}_{2}$ & $2587 \pm 623$ & $429 \pm 39$ \\
Vinylester & $\mathrm{Neat}$ & $3942 \pm 807$ & $830 \pm 343$ \\
& $\mathrm{scCO}_{2}$ & $3345 \pm 490$ & $673 \pm 145$ \\
\hline
\end{tabular}

In fact, it is important to highlight that the vinylester resin selected for this experimental work is a quite innovative styrene-free resin in which the styrene monomer is replaced by 1,4-butanediol dimethacrylate (BDDMA). Recently, Bénéthuilière et al. [51] investigated the potential of a styrene-free resin on the adhesion level of E-glass fibers by performing the microbond test. As in the present study, the BDDMA was used as a reactive diluent for the styrene-free resin and the results were compared with those found with a conventional vinylester resin. The authors reported that the styrene-free resin displayed a lower ability than a conventional vinylester resin to wet E-glass fibers having a vinylester-compatible sizing. This phenomenon is due to the fully dispersive nature of the styrene-free resin, while the E-glass fibers have a much higher polar characteristic. Flax yarns are characterized by a strongly polar behavior that can explain the low compatibility with the fully dispersive styrene-free vinylester resin.

The interfacial shear strength value (IFSS) was estimated in order to describe the yarn/matrix interface adhesion quality in accordance with the model proposed by Kelly and Tyson [52]:

$$
I F S S=\frac{\sigma_{f}\left(l_{c}\right) \cdot d}{2 \cdot l_{c}}
$$


where $d$ is the yarn diameter, $l_{c}$ is the critical fragment length, and $\sigma_{f(l c)}$ is the yarn strength at a length equal to the critical filament length. This strength value was determined by extrapolation of the Weibull cumulative distribution function obtained for only one given yarn gauge length $l_{0}$ (Equation (5)).

$$
\sigma_{f}\left(l_{c}\right)=\sigma_{f}\left(l_{0}\right)\left(\frac{l_{0}}{l_{c}}\right)^{-\frac{1}{m}}
$$

where $m$ is the shape parameter of the Weibull distribution for the tested gauge length $l_{0}$ of $40 \mathrm{~mm}, l_{c}$ is the critical fragment length, and $\sigma_{f(l 0)}$ is the strength value at the gauge length. The results of this analysis are summarized in Table 5.

Table 5. Strength values at critical fragment length and interfacial shear strength values (IFSS) for the different flax/epoxy and flax/vinylester systems.

\begin{tabular}{cccc}
\hline Matrix & Flax Yarn & $\boldsymbol{\sigma}_{\mathbf{f}}\left(\mathbf{l}_{\mathbf{c}}\right)[\mathbf{M P a}]$ & IFSS [MPa] \\
\hline Epoxy & Neat & $406 \pm 18$ & $19.3 \pm 3.7$ \\
& $\mathrm{scCO}_{2}$ & $312 \pm 10$ & $15.7 \pm 2.1$ \\
Vinylester & $\mathrm{Neat}$ & $376 \pm 15$ & $13.9 \pm 2.8$ \\
& $\mathrm{scCO}_{2}$ & $300 \pm 6$ & $14.3 \pm 2.6$ \\
\hline
\end{tabular}

The difficulty in adapting the fragmentation test to yarns stems from the cross-sectional area measurement of the yarn that typically includes voids between the fibers that are then replaced by matrix during the impregnation step of the single yarn. Therefore, IFSS values were calculated but in the present case, their numerical values need to be considered only on a qualitative level to rank the different flax yarns.

IFSS values for neat flax yarns confirm the better interfacial adhesion with the epoxy matrix. Particularly interesting are the interfacial shear strength values obtained for the $\mathrm{scCO}_{2}$ treated flax yarn/vinylester system. This treatment did not significantly reduce the tensile properties of flax yarns (Table 3). It is, therefore, possible to directly compare the IFSS values obtained after the $\mathrm{scCO}_{2}$ treatment with those found for the as-received flax yarn. Considering the flax/vinylester system, a slight increase in the interfacial adhesion is produced after the exposure of flax yarn to the supercritical fluid. On the contrary, a decrease in IFSS value is reported with the epoxy matrix. However, as previously mentioned, the exposure to the supercritical fluid caused an increase in the average diameter of yarns, which resulted in a slight reduction in the tensile strength value. This reduction explains the decrease in the IFSS values found for the flax/epoxy system, being the IFSS results strictly dependent on any variation in the mechanical properties of flax yarns produced by the surface modification treatment. The values reported in Table 5 highlight that the two thermoset systems exhibited different IFSS results. The flax/epoxy samples are characterized by higher values of interfacial shear strength than the flax/vinylester ones. This result confirmed once again the better adhesion quality between flax yarn and epoxy resin than that observed for the vinylester matrix.

The issues previously raised about the use of the fragmentation test at the yarn scale can be addressed by considering another parameter, i.e., the length of the debonding zone between the flax yarns and the matrix [53,54]. The higher is the debonding length, the lower is the adhesion quality between the filament and the polymer matrix (Figure 7), being this value independent of the constraints that should be met for a valid SFFT (for instance, no change in mechanical properties of the fiber after surface treatment). The results (Table 4) showed that the $\mathrm{scCO}_{2}$ treatments produced a decrease in the length of the debonding zone, promoting the interfacial adhesion of flax yarns with the epoxy and, in particular, with the vinylester resin. This result is consistent with the critical filament length values previously reported (Table 4) and it points out that the supercritical carbon dioxide fluid can successfully promote the adhesion of flax yarns with the vinylester matrix. This positive effect produced on the flax yarn/matrix adhesion can be linked to the non-cellulosic constituents' removal, 
such as lignin, pectin, and hemicellulose, occurred during the $\mathrm{scCO}_{2}$ process and confirmed by TGA and FT-IR measurements. The debonding length values found for the epoxy matrix samples are lower than the values found for the vinylester matrix ones. These results are again consistent with the critical filament length and IFSS values and highlight the better compatibility of flax yarns with the epoxy matrix than with the vinylester one.

The debonding length results were also confirmed by micro-computed tomography, with which a post-mortem examination of the single yarn composites enabled precise measurement of the yarn/matrix debonding zone. The debonding length was identified by the black voxels corresponding to voids between the periphery of the flax yarn and the matrix (Figure 8). If compared to untreated flax yarns [49], the microtomographic images for the supercritical $\mathrm{CO}_{2}$ treated flax/matrix samples confirmed the decrease in debonding length with both epoxy and vinylester resin. The presence of some resin cracks inside the vinylester matrix, identified by a blue arrow in Figure 8B, supports the increase in compatibility and the enhancement in load transfer ability between the treated flax yarn and the vinylester polymer matrix.
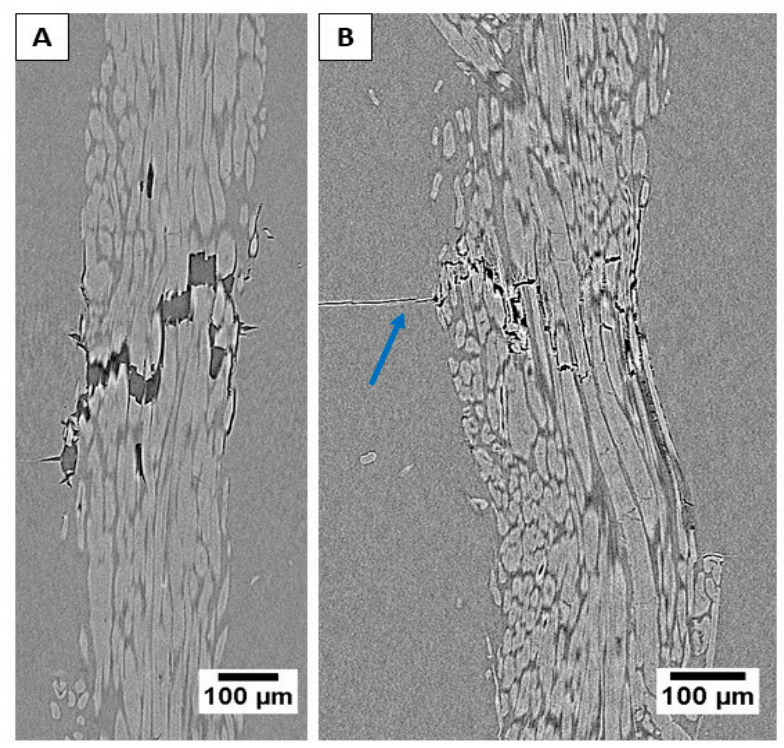

Figure 8. Debonding length observation by micro-computed tomography. High-resolution micro-CT images for supercritical $\mathrm{CO}_{2}$ treated flax/epoxy (A) and flax/vinylester $(\mathbf{B})$ single yarn samples.

\section{Materials and Methods}

\subsection{Raw Materials}

As regards the plant reinforcement, a Biotex flax fabric (Linum usitatissimum), supplied by Composites Evolution (Chesterfield, UK), was used. This fabric, a $2 \times 2$ twill fabric $\left(200 \mathrm{~g} / \mathrm{m}^{2}\right)$, is commercialized without any specific sizing and individual flax yarns were carefully extracted by hand. Two different thermoset matrices were included in this study, an epoxy and a vinylester resin. As regards the epoxy system, an Epoxy Prime 27 infusion resin and PRIME 20 slow hardener by GURIT (Newport, UK) were used. The curing process was carried out with a recommended mixing ratio of 100:28 by weight. In order to reduce the risks derived from styrene, a quite innovative styrene-free vinylester resin was selected. Specifically, the Advalite VH-1207 vinylester infusion resin, supplied by Reichhold (London, UK), was chosen. The Norpol Peroxide PMEC N24 hardener, supplied by Reichhold, was used as curing agent and the curing process was carried out with a mixing ratio of 1 phr. The resin is pre-accelerated for room temperature cure. 


\subsection{Supercritical Carbon Dioxide $\left(\mathrm{scCO}_{2}\right)$ Treatment of Flax Yarns}

Flax yarns were treated using a piece of equipment supplied by Separex (Nancy, France). The flax yarns were first placed in a temperature and pressure-controlled enclosure. A schematic representation of the equipment setup used is reported in Figure 9. Gaseous carbon dioxide (1) was extracted from a bottle by a valve (2) at the beginning of the process. It was then cooled to a liquid state (3) and directed toward a pump (4), which controlled the pressure. When it reached the pressure needed for the supercritical state (up to the critical point of $73.8 \mathrm{bar}$ ), the carbon dioxide was heated by a heat exchanger (5). At the supercritical state, the $\mathrm{CO}_{2}$ was directed toward the autoclave (6), which contained the flax yarn samples (7). Thermocouples were used to control the temperature (8). The treatment of flax in autoclave was carried out under high temperature and pressure conditions $\left(130^{\circ} \mathrm{C}\right.$, $50 \mathrm{bar}$ ) for a duration of $170 \mathrm{~min}$. When the treatment was finished, the carbon dioxide was recovered (9), cooled, and directed toward a recycling line. The amount of $\mathrm{CO}_{2}$ injected in the reactor was measured and controlled using a balance. After the process, the reactor was depressurized from 150 bar to 0 bar to allow its opening and the samples were stored at room temperature for cooling.

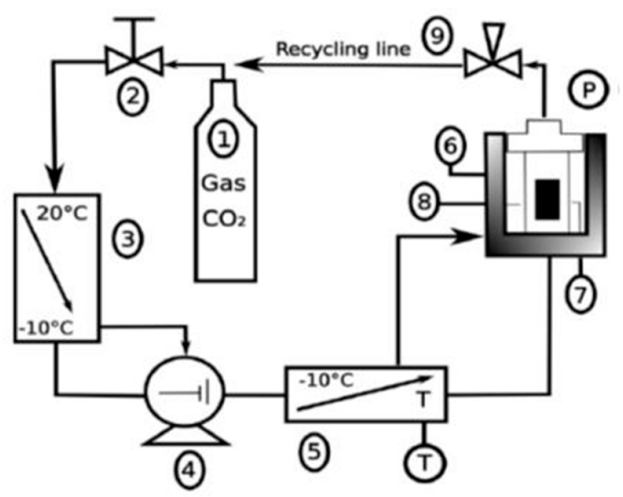

Figure 9. Schematic diagram of the supercritical equipment provided by Separex.

\subsection{Tensile Testing of Flax Yarns}

Tensile properties of untreated and $\mathrm{scCO}_{2}$ treated flax yarns were determined by single yarn tensile tests in accordance with ASTM C-1557 standard test method [21,49]. Tensile tests were carried out at room temperature using a Zwick/Roell Z010 machine (Ulm, Germany) equipped with a $1 \mathrm{kN}$ load cell. Each test was performed in displacement control at a cross-head speed of $2 \mathrm{~mm} / \mathrm{min}$. Individual flax yarns were carefully separated by hand from the fabric and glued (Loctite ${ }^{\mathrm{TM}}$ Gel Superglue, Milan, Italy) onto a card tab with a central window cut out to match the gauge length of $40 \mathrm{~mm}$. At least 20-30 yarns were tested for each type of yarns. Before testing, all yarns were conditioned at $45^{\circ} \mathrm{C}$ for $24 \mathrm{~h}$. Before each test, the yarn diameter was evaluated as the average of at least ten measurements along the gauge length by optical microscopy.

\subsection{Fourier Transform Infrared Spectroscopy Analysis (FT-IR)}

The chemical composition of the as-received and $\mathrm{scCO}_{2}$ treated flax yarns has been studied by Fourier-transform infrared (FT-IR) analysis. Infrared measurements were carried out with a Bruker Vertex 70 spectrometer (Bruker Optik $\mathrm{GmbH}$, Ettlingen, Germany) equipped with a single reflection Diamond ATR cell. Spectra were recorded with a $3 \mathrm{~cm}^{-1}$ spectral resolution in the mid-infrared range (400-4000 $\mathrm{cm}^{-1}$ ) using 512 scans.

\subsection{Thermogravimetric Analysis (TGA)}

The thermal stability of untreated and treated flax yarns has been investigated using a SetSys Evolution (Setaram Instrumentation, Caluire France) thermogravimetric analyzer. The different samples were placed in an alumina pan and heated at a rate of $10^{\circ} \mathrm{C} / \mathrm{min}$ to a maximum temperature 
of $800{ }^{\circ} \mathrm{C}$ in nitrogen atmosphere. Weight changes versus temperature and the derivative of weight changes versus temperature have been recorded.

\subsection{Single Yarn Fragmentation Test}

In order to assess the interfacial properties of untreated and $\mathrm{scCO}_{2}$ treated flax yarns with epoxy and vinylester matrices, the well-known single fiber fragmentation test (SFFT) was slightly modified and adapted to test single yarns, as reported in our previous publications [21,49]. A dedicated metallic mould has been used for manufacturing composite specimens reinforced with a single flax yarn aligned along the applied tensile load. Each flax yarn was positioned in the mould and held in place by adhesive tape. Before matrix casting, flax yarns were conditioned at $45^{\circ} \mathrm{C}$ for $24 \mathrm{~h}$. The specimens showed a dog bone shape with reduced gage section characterized by a length of $15 \mathrm{~mm}$, a thickness of $2 \mathrm{~mm}$, and a width of $3 \mathrm{~mm}$. An Instron E1000 ElectroPuls test machine (Norwood, MA, USA) with a load cell of $2 \mathrm{kN}$ was used for the fragmentation test with a crosshead speed of $0.005 \mathrm{~mm} / \mathrm{min}$. Before each test, the yarn diameter was evaluated as the average of at least ten measurements along the gauge length by optical microscopy (Zeiss, Oberkochen, Germany. The test was carried out at a rather low loading rate and the loading phase was stopped if the specimen failed, or when the fragmentation saturation level was achieved. This last case was defined when no new filament breaks appeared during a subsequent strain increase by $0.5 \%$, as reported in literature [55].

In order to be sure to reach the saturation level, epoxy- and vinylester-based specimens were loaded up to strains higher than $9 \%$ and $11 \%$, respectively. All flax yarns were characterized by a strain at failure at least three and two times smaller than the failure strain of both epoxy and vinylester resins, respectively, thus ensuring the compliance with the Kelly-Tyson model requirements [52].

\subsection{X-ray Microtomography}

An UltraTom CT scanner manufactured by RX Solutions (Chavanod, France) has been used for the analysis of single yarn composites with a resolution of $1.5 \mu \mathrm{m}$, an accelerating voltage of $50 \mathrm{kV}$, and a beam current of $157 \mu \mathrm{A}$.

\subsection{Optical and FE-SEM Observations}

The flax yarn diameters, as well as the fragment lengths, were measured by using a ZEISS Axio Imager optical microscope (Oberkochen, Germany). A morphological investigation of $\mathrm{scCO}_{2}$ treated and untreated flax yarns was carried out using a field-emission gun scanning electron microscope (FE-SEM) Zeiss Auriga. All specimens were sputter-coated with chromium prior to FE-SEM observation.

\section{Conclusions}

Commercially available flax yarns were subjected to a supercritical $\mathrm{CO}_{2}$ treatment with the aim of modifying their interfacial adhesion with two different thermoset matrices, namely an epoxy and a vinylester resin. This green treatment was found to alter the biochemical composition of flax fibers, as confirmed by FT-IR and TGA analyses, which highlighted the preferential removal of hemicellulose, lignin, and pectin with a general cleaning effect of fiber surface but without degradation of their thermal stability. These constituents are mostly responsible for the highly polar behavior of flax fibers, thus suggesting a potential reduction of moisture sensitivity and a general increase in fiber/matrix compatibility. This assumption was confirmed by single yarn fragmentation tests, where the debonding and critical fragment length values were reduced after the exposure to the supercritical fluid, in particular with reference to the fully dispersive vinylester matrix. These preliminary results suggest the potential of this treatment as an attractive green method to tailor the surface compatibility of lignocellulosic fibers, even though there is still room for optimizing the process parameters (temperature, pressure, and exposure time) and their effects on fibers' physico-mechanical properties. 
Author Contributions: Conceptualization, F.S., F.T., and L.C.-A.; methodology, F.S., V.P., and F.T.; validation, F.S., J.T., and M.C.S.; formal analysis, M.C.S.; investigation, M.C.S., C.F., L.P., and M.P.B.; data curation, M.C.S., L.C.-A., and J.T.; writing-original draft preparation, M.C.S., F.T., and F.S.; writing-review and editing, V.P., M.P.B., and J.T.; visualization, M.C.S.; supervision, F.S., F.T., V.P., and L.P. All authors have read and agreed to the published version of the manuscript.

Funding: This research received no external funding.

Conflicts of Interest: The authors declare no conflict of interest.

\section{References}

1. Bourmaud, A.; Beaugrand, J.; Shaf, D.U.; Placet, V.; Baley, C. Towards the design of high-performance plant fibre composites. Prog. Mater. Sci. 2018, 97, 347-408. [CrossRef]

2. Baley, C.; Gomina, M.; Breard, J.; Bourmaud, A.; Drapier, S.; Ferreira, M.; Le Duigou, A.; Liotier, P.J.; Ouagne, P.; Soulat, D.; et al. Specific features of flax fibres used to manufacture composite materials. Int. J. Mater. Form. 2019, 12, 1023-1052. [CrossRef]

3. Haag, K.; Padovani, J.; Fita, S.; Trouvé, J.P.; Pineau, C.; Hawkins, S.; De Jong, H.; Deyholos, M.K.; Chabbert, B.; Müssig, J.; et al. Influence of flax fibre variety and year-to-year variability on composite properties. Ind. Crops Prod. 2017, 98, 1-9. [CrossRef]

4. Morvan, C.; Andème-Onzighi, C.; Girault, R.; Himmelsbach, D.S.; Driouich, A.; Akin, D.E. Building flax fibres: More than one brick in the walls. Plant Physiol. Biochem. 2003, 41, 935-944. [CrossRef]

5. Bourmaud, A.; Gibaud, M.; Lefeuvre, A.; Morvan, C.; Baley, C. Influence of the morphology characters of the stem on the lodging resistance of Marylin flax. Ind. Crops Prod. 2015, 66, 27-37. [CrossRef]

6. Goudenhooft, C.; Bourmaud, A.; Baley, C. Varietal selection of flax over time: Evolution of plant architecture related to influence on the mechanical properties of fibers. Ind. Crops Prod. 2017, 97, 56-64. [CrossRef]

7. Baley, C.; Gomina, M.; Breard, J.; Bourmaud, A.; Davies, P. Variability of mechanical properties of flax fibres for composite reinforcement. A review. Ind. Crops Prod. 2019, 111984. [CrossRef]

8. Pickering, K.L.; Aruan Efendy, M.G.; Le, T.M. A review of recent developments in natural fibre composites and their mechanical performance. Compos. Part A Appl. Sci. Manuf. 2016, 83, 98-112. [CrossRef]

9. Kalia, S.; Kaith, B.S.; Kaur, I. Pretreatments of natural fibers and their application as reinforcing material in polymer composites-A review. Polym. Eng. Sci. 2009, 49, 1253-1272. [CrossRef]

10. Li, X.; Tabil, L.G.; Panigrahi, S. Chemical Treatments of Natural Fiber for Use in Natural Fiber-Reinforced Composites: A Review. J. Polym. Environ. 2007, 15, 25-33. [CrossRef]

11. Liu, M.; Thygesen, A.; Summerscales, J.; Meyer, A.S. Targeted pre-treatment of hemp bast fibres for optimal performance in biocomposite materials: A review. Ind. Crops Prod. 2017, 108, 660-683. [CrossRef]

12. Huo, S.; Thapa, A.; Ulven, C.A. Effect of surface treatments on interfacial properties of flax fiber-reinforced composites. Adv. Compos. Mater. 2013, 22, 109-121. [CrossRef]

13. Sinha, E.; Rout, S.K. Influence of fibre-surface treatment on structural, thermal and mechanical properties of jute fibre and its composite. Bull. Mater. Sci. 2009, 32, 65-76. [CrossRef]

14. Bulut, Y.; Aksit, A. A comparative study on chemical treatment of jute fiber: Potassium dichromate, potassium permanganate and sodium perborate trihydrate. Cellulose 2013, 20, 3155-3164. [CrossRef]

15. Amiri, A.; Ulven, C.; Huo, S. Effect of Chemical Treatment of Flax Fiber and Resin Manipulation on Service Life of Their Composites Using Time-Temperature Superposition. Polymers 2015, 7, 1965-1978. [CrossRef]

16. Sever, K.; Sarikanat, M.; Seki, Y.; Erkan, G.; Erdoĝan, Ü.H.; Erden, S. Surface treatments of jute fabric: The influence of surface characteristics on jute fabrics and mechanical properties of jute/polyester composites. Ind. Crops Prod. 2012, 35, 22-30. [CrossRef]

17. Van de Weyenberg, I.; Chi Truong, T.; Vangrimde, B.; Verpoest, I. Improving the properties of UD flax fibre reinforced composites by applying an alkaline fibre treatment. Compos. Part A Appl. Sci. Manuf. 2006, 37, 1368-1376. [CrossRef]

18. Yuan, X.; Jayaraman, K.; Bhattacharyya, D. Plasma treatment of sisal fibres and its effects on tensile strength and interfacial bonding. J. Adhes. Sci. Technol. 2002, 16, 703-727. [CrossRef]

19. Bozaci, E.; Sever, K.; Sarikanat, M.; Seki, Y.; Demir, A.; Ozdogan, E.; Tavman, I. Effects of the atmospheric plasma treatments on surface and mechanical properties of flax fiber and adhesion between fiber-matrix for composite materials. Compos. Part B Eng. 2013, 45, 565-572. [CrossRef] 
20. Kim, S.W.; Oh, S.; Lee, K. Variation of mechanical and thermal properties of the thermoplastics reinforced with natural fibers by electron beam processing. Radiat. Phys. Chem. 2007, 76, 1711-1714. [CrossRef]

21. Seghini, M.C.; Touchard, F.; Sarasini, F.; Chocinski-Arnault, L.; Tirillò, J.; Bracciale, M.P.; Zvonek, M.; Cech, V. Effects of oxygen and tetravinylsilane plasma treatments on mechanical and interfacial properties of flax yarns in thermoset matrix composites. Cellulose 2019, 27, 511-530. [CrossRef]

22. Wang, W.; Xian, G.; Li, H. Surface modification of ramie fibers with silanized CNTs through a simple spray-coating method. Cellulose 2019, 26, 8165-8178. [CrossRef]

23. Sarker, F.; Karim, N.; Afroj, S.; Koncherry, V.; Novoselov, K.S.; Potluri, P. High-Performance Graphene-Based Natural Fiber Composites. ACS Appl. Mater. Interfaces 2018, 10, 34502-34512. [CrossRef]

24. Ajith, A.; Xian, G.; Li, H.; Sherief, Z.; Thomas, S. Surface grafting of flax fibres with hydrous zirconia nanoparticles and the effects on the tensile and bonding properties. J. Compos. Mater. 2016, 50, 627-635. [CrossRef]

25. Lakshmanan, A.; Chakraborty, S. Coating of silver nanoparticles on jute fibre by in situ synthesis. Cellulose 2017, 24, 1563-1577. [CrossRef]

26. Zhuang, R.C.; Doan, T.T.L.; Liu, J.W.; Zhang, J.; Gao, S.L.; Mäder, E. Multi-functional multi-walled carbon nanotube-jute fibres and composites. Carbon 2011, 49, 2683-2692. [CrossRef]

27. Wang, H.; Xian, G.; Li, H. Grafting of nano-TiO2 onto flax fibers and the enhancement of the mechanical properties of the flax fiber and flax fiber/epoxy composite. Compos. Part A Appl. Sci. Manuf. 2015, 76, 172-180. [CrossRef]

28. Zhang, X.; Heinonen, S.; Levänen, E. Applications of supercritical carbon dioxide in materials processing and synthesis. RSC Adv. 2014, 4, 61137-61152. [CrossRef]

29. Sanli, D.; Bozbag, S.E.; Erkey, C. Synthesis of nanostructured materials using supercritical $\mathrm{CO}_{2}$ : Part I. Physical transformations. J. Mater. Sci. 2012, 47, 2995-3025. [CrossRef]

30. Yeo, S.D.; Kiran, E. Formation of polymer particles with supercritical fluids: A review. J. Supercrit. Fluids 2005, 34, 287-308. [CrossRef]

31. Campbell, M.L.; Apodaca, D.L.; Yates, M.Z.; McCleskey, T.M.; Birnbaum, E.R. Metal Extraction from Heterogeneous Surfaces Using Carbon Dioxide Microemulsions. Langmuir 2001, 17, 5458-5463. [CrossRef]

32. Narayanaswamy, N.; Faik, A.; Goetz, D.J.; Gu, T. Supercritical carbon dioxide pretreatment of corn stover and switchgrass for lignocellulosic ethanol production. Bioresour. Technol. 2011, 102, 6995-7000. [CrossRef] [PubMed]

33. Li, L.; Kiran, E. Interaction of supercritical fluids with lignocellulosic materials. Ind. Eng. Chem. Res. 1988, 27, 1301-1312. [CrossRef]

34. Schmidt, A.; Bach, E.; Schollmeyer, E. Damage to Natural and Synthetic Fibers Treated in Supercritical Carbon Dioxide at 300 bar and Temperatures up to $160^{\circ}$ C. Text. Res. J. 2002, 72, 1023-1032. [CrossRef]

35. Daza Serna, L.V.; Orrego Alzate, C.E.; Cardona Alzate, C.A. Supercritical fluids as a green technology for the pretreatment of lignocellulosic biomass. Bioresour. Technol. 2016, 199, 113-120. [CrossRef] [PubMed]

36. Gutiérrez, M.C.; Rosa, P.d.T.V.; De Paoli, M.A.; Felisberti, M.I. Biocompósitos de acetato de celulose e fibras curtas de Curauá tratadas com $\mathrm{CO}_{2}$ supercrítico. Polimeros 2012, 22, 295-302. [CrossRef]

37. Francois, C.; Plasseraud, L.; Pourchet, S.; Boni, G.; Placet, V.; Fontaine, S.; Beaugrand, J.; Champion, D. Étude d'un procédé de traitement innovant des fibres de chanvre sous condition de fluide supercritique et propriétés induites. In Proceedings of the Journées Nationales sur les Composites 20, Champs sur Marne, France, 28-30 July 2017; pp. 1-10.

38. Francois, C.; Placet, V.; Beaugrand, J.; Pourchet, S.; Boni, G.; Champion, D.; Fontaine, S.; Plasseraud, L. Can supercritical carbon dioxide be suitable for the green pretreatment of plant fibres dedicated to composite applications? J. Mater. Sci. 2020, 55, 4671-4684. [CrossRef]

39. Zhang, J.; Zheng, H.; Zheng, L. Effect of treatment temperature on structures and properties of flax rove in supercritical carbon dioxide. Text. Res. J. 2018, 88, 155-166. [CrossRef]

40. Reddy, K.O.; Maheswari, C.U.; Reddy, K.R.; Shukla, M.; Muzenda, E.; Rajulu, A.V. Effect of Chemical Treatment and Fiber Loading on Mechanical Properties of Borassus (Toddy Palm) Fiber/Epoxy Composites. Int. J. Polym. Anal. Charact. 2015, 20, 612-626. [CrossRef]

41. Sanjay, M.R.; Siengchin, S.; Parameswaranpillai, J.; Jawaid, M.; Pruncu, C.I.; Khan, A. A comprehensive review of techniques for natural fibers as reinforcement in composites: Preparation, processing and characterization. Carbohydr. Polym. 2019, 207, 108-121. 
42. Gao, S.H.; Yu, C.W. Effects of supercritical carbon dioxide on morphology of apocynum venetum fibers. Therm. Sci. 2015, 19, 1279-1282. [CrossRef]

43. Abidi, N.; Manike, M. X-ray diffraction and FTIR investigations of cellulose deposition during cotton fiber development. Text. Res. J. 2018, 88, 719-730. [CrossRef]

44. Abidi, N.; Cabrales, L.; Haigler, C.H. Changes in the cell wall and cellulose content of developing cotton fibers investigated by FTIR spectroscopy. Carbohydr. Polym. 2014, 100, 9-16. [CrossRef] [PubMed]

45. Van de Velde, K.; Baetens, E. Thermal and Mechanical Properties of Flax Fibres as Potential Composite Reinforcement. Macromol. Mater. Eng. 2001, 286, 342-349. [CrossRef]

46. Mazian, B.; Bergeret, A.; Benezet, J.C.; Malhautier, L. Influence of field retting duration on the biochemical, microstructural, thermal and mechanical properties of hemp fibres harvested at the beginning of flowering. Ind. Crops Prod. 2018, 116, 170-181. [CrossRef]

47. Spinacé, M.A.S.; Lambert, C.S.; Fermoselli, K.K.G.; De Paoli, M.A. Characterization of lignocellulosic curaua fibres. Carbohydr. Polym. 2009, 77, 47-53. [CrossRef]

48. Brebu, M.; Vasile, C. Thermal degradation of lignin-A review. Cellul. Chem. Technol. 2010, 44, $353-363$.

49. Seghini, M.C.; Touchard, F.; Sarasini, F.; Chocinski-Arnault, L.; Mellier, D.; Tirillò, J. Interfacial adhesion assessment in flax/epoxy and in flax/vinylester composites by single yarn fragmentation test: Correlation with micro-CT analysis. Compos. Part A Appl. Sci. Manuf. 2018, 113, 66-75. [CrossRef]

50. Fraser, W.A.; Ancker, F.H.; Dibenedetto, A.T.; Elbirli, B. Evaluation of surface treatments for fibers in composite materials. Polym. Compos. 1983, 4, 238-248. [CrossRef]

51. Bénéthuilière, T.; Duchet-Rumeau, J.; Gérard, J.F.; Dubost, E.; Peyre, C. Physico-chemistry of vinylester/glass fiber interfaces used in SMC composites. In Proceedings of the 20th International Conference on Composite Materials (ICCM20), Copenhagen, Denmark, 19-24 July 2015; pp. 1-12.

52. Kelly, A.; Tyson, W.R. Tensile properties of fibre-reinforced metals: Copper/tungsten and copper/molybdenum. J. Mech. Phys. Solids 1965, 13, 329-338. [CrossRef]

53. Kim, B.W.; Nairn, J.A. Observations of Fiber Fracture and Interfacial Debonding Phenomena Using the Fragmentation Test in Single Fiber Composites. J. Compos. Mater. 2002, 36, 1825-1858. [CrossRef]

54. Ramirez, F.A.; Carlsson, L.A.; Acha, B.A. Evaluation of water degradation of vinylester and epoxy matrix composites by single fiber and composite tests. J. Mater. Sci. 2008, 43, 5230-5242. [CrossRef]

55. Joffe, R.; Andersons, J.; Wallström, L. Interfacial shear strength of flax fiber/thermoset polymers estimated by fiber fragmentation tests. J. Mater. Sci. 2005, 40, 2721-2722. [CrossRef]

Sample Availability: Samples of the tested specimens are available from the authors.

(C) 2020 by the authors. Licensee MDPI, Basel, Switzerland. This article is an open access article distributed under the terms and conditions of the Creative Commons Attribution (CC BY) license (http://creativecommons.org/licenses/by/4.0/). 